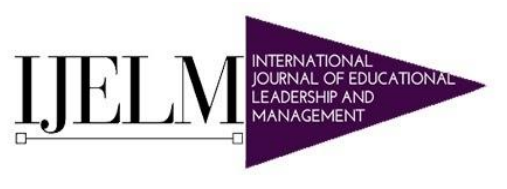

Hipatia Press

www.hipatiapress.com

Instructions for authors, subscriptions and further details:

http://ijelm.hipatiapress.com

\title{
Contemporary Educational Leadership and its Role in Converting Traditional Schools into Professional Learning Communities.
}

Mofareh Alkrdem ${ }^{1}$

1) King Khalid University, Saudi Arabia.

Date of publication: July $16^{\text {th }}, 2020$

Edition period: July 2019 - July 2020

To cite this article: Alkrdem, M. (2020). Contemporary Educational Leadership and its Role in Converting Traditional Schools into Professional Learning Communities. International Journal of Educational Leadership and Management

doi: $10.17583 /$ ijelm.2020.4298

To link this article: http://dx.doi.org/10.17583/ijelm.2020.4298

\section{PLEASE SCROLL DOWN FOR ARTICLE}

The terms and conditions of use are related to the Open Journal System and to Creative Commons Attribution License (CCAL). 


\section{Contemporary Educational Leadership and its Role in Converting Traditional Schools into Professional Learning Communities.}

Mofareh Alkrdem

King Khalid University

Saudi Arabia

\section{Abstract}

The dynamics of school as a single source of knowledge have changed, which eliminate the organizational obstacles that hinder its learning process and endeavor towards the construction of a leadership competence. The ability of an organization to construct and support the professional learning communities depends on its ability to improve and support an individual. This study therefore aims to investigate the role of contemporary educational leadership in converting traditional schools into professional learning communities. The current study has adopted one of the developmental approaches that simultaneously represent contemporary trends in improving the school. An increase is found among the school staff related to the improvement and development of the project concerning its planning, organizing, implementation, and evaluation. The implementation of reformative perspective increases the desire towards the implementation of decentralization. The work teams are successful in fulfilling all tasks and solving the problems that are encountered by the leaders and members of the team. The concern towards investment in the information and communication technology has been growing to build the leadership capacities of the members of teamwork.

Keywords: Contemporary Educational Leadership, Traditional School, Professional Learning Communities. 


\title{
El liderazgo educativo contemporáneo y su papel en la conversión de las escuelas tradicionales en comunidades de aprendizaje profesional.
}

\author{
Mofareh Alkrdem \\ King Khalid University \\ Saudi Arabia
}

\section{Resumen}

La dinámica de la escuela como fuente única de conocimiento ha cambiado, lo que elimina los obstáculos organizativos que obstaculizan su proceso de aprendizaje y se esfuerza por construir una competencia de liderazgo. La capacidad de una organización para construir y apoyar las comunidades de aprendizaje profesional depende de su capacidad para mejorar y apoyar a un individuo. Por lo tanto, este estudio tiene como objetivo investigar el papel del liderazgo educativo contemporáneo en la conversión de las escuelas tradicionales en comunidades de aprendizaje profesional. El estudio actual ha adoptado uno de los enfoques de desarrollo que representan simultáneamente las tendencias contemporáneas para mejorar la escuela. Se encuentra un aumento entre el personal escolar relacionado con la mejora y el desarrollo del proyecto con respecto a su planificación, organización, implementación y evaluación. La implementación de la perspectiva reformativa aumenta el deseo hacia la implementación de la descentralización. Los equipos de trabajo tienen éxito en cumplir con todas las tareas y resolver los problemas que enfrentan los líderes y los miembros del equipo. La preocupación por la inversión en la tecnología de la información y la comunicación ha ido creciendo para desarrollar las capacidades de liderazgo de los miembros del trabajo en equipo.

Palabras clave: Liderazgo Educativo Contemporáneo, Escuela Tradicional, Comunidades de Aprendizaje Profesional. 


\section{Alkrdem - Contemporary Educational Leadership}

卫

He process of transforming schools into professional learning community is grounded on the availability of leadership type. It their participation in the process of forming a decision, which urges them to learn collaboratively by forming learning teams. These principles have led to a wide range perspective that primarily focuses on the learning of the leaders, teachers, administrators, students, parents, and members of local society. Moilanen (2001) mentioned that the learning organization needs to operate in a well-organized and rational way by focusing on the learning process. This practice has been observed as one of the fundamental elements that shape the school views, values, and daily routines. The professional learning communities can become a strong stimulus to professional development and an effective strategy that aims to develop and change the schools. The learning community is defined as the general atmosphere, in which all the staff participates in a responsible way for learning and enhancing their performance in a practical way to achieve their ultimate goal. Therefore, the organization needs to eliminate the organizational obstacles that hinder the learning process and infuse its effort towards the construction of a leadership competence. This would assist the individuals to achieve their ultimate goals and which further provides support to the organizational structures for facilitating the process of organizational and individual learning.

Professional Learning Communities have been defined as a place, where the school administration and the teachers are in a continuous endeavor to participate in learning. Moreover, teachers aim to enhance their professional effectiveness that will be beneficial to learners and called the development and continuous research community (Hord, 1997). The learning community may also be defined as a group of people, who interact with each other and with the surrounding environment in a direct or digitalized manner. This helps in developing a shared vision and various specializations which motivates the team spirit. The school improvement can be defined as the ability of a school to reformulate its criteria, values, policies, and structures, apart from drafting its plans and formulating strategies. Moreover, Kimber (2003) defines it as a group of activities and actions that are initiated by the 
leader, shaping the leadership ways. The concept of the PLC thus calls a reassessment to enact new strategies as schools have a tendency towards deproblematisation using pedagogisation. This tendency is also clear in some of the research literature. It is claimed that there is an empirical consensus on a set of core aspects and a conceptual framework for teacher learning (Watson, 2014).

The problem that the current study has addressed is the negativity of the school environment, where the absence of team spirit-centered prevails considering the basic deficiency of the shared vision, cooperative learning, and work. Moreover, several school principals are still using conventional types of leadership, where dictatorship dominance prevails within the schools (Sulaiman, 2009). The autocratic style limits the capacity of principals in engaging teachers in the process of decision-making at school (Muhammad, 2009). The decisions are exclusively made by principal without real participation of the teachers (Al-Husaini, \& Zaghlool, 2005). Developing an apparent case for a vivid and present need for educational transformation is not an overwhelmingly complex task, given that media sometimes does not portray education effectively. This requirement has allowed policymakers, parents, and educators for searching approaches to enhance transformation and student achievement in schools. It is also recommended that value-added modeling is one of the major approaches to enhance public schools that is intended to improve human capital (Bennett, 2017).

Therefore, this study aims to investigate the role of contemporary educational leadership in converting traditional schools into professional learning communities. The study further aims to analyze the concept of professional learning communities. It has also stated basic constituents of professional learning communities and identified the ideological basis to change schools into professional learning communities by adopting some contemporary manners. The presumptions obtained from this study will be beneficial for school administrators in effectively managing and planning the implementation of a PLC within a school. Moreover, a foundation for professional development will be achieved through this information throughout a school. Lastly, this study will garner information relating to 


\section{Alkrdem - Contemporary Educational Leadership}

how educators or teachers embrace working mutually within a PLC and how teaching practices influence student educational outcomes.

\section{The Concept of Professinal Learning Communities}

The professional learning communities are composed of a group of people who share goals and cooperation to identify the point of strength in each individual. They also respect the diversity of views and support the learning opportunities effectively in a way that leads to the cooperative and active environment. In addition to the high development of members' capacities, professional learning communities can produce new knowledge and work to exchange it (Kilpatrick, Jones \& Barrett, 2003). According to Melton (2007), the professional learning communities are defined as a small group that encompasses teachers, students, and administrators, possessing a clear feeling of belongingness, shared goals, and opportunities for face-toface interaction. Whereas, Cormier, Olivier \& Lafayette (2009) have defined the professional learning communities as a group of individuals, who formulate a team and instill cooperation among them for their continuous improvement, which can be meet through a shared vision focusing on curriculum. According to Gwin (2008), it is a group of people, who have problems and have shared emotions on a certain topic. They work to deepen their knowledge and experiences in this regard is through the continuous improvement. Professional learning communities are characterized by several traits identified by Dettinger and Brower (2003), which include integration of learning in every work performed, encouraging and rewarding learning for its sake, and supporting the teamwork, innovation, quality, and empowerment. Along with it, it is also inclusive of confident staff that encourages to attend the necessary training courses while also fostering collaborative learning across various divisions.

Huffman and Hipp (2001) defined the importance of shifting schools into communities, where professional learning is continuous and reflective, which mainly focuses on the enhancement of learning outcomes. The construction of such a community is based on three important and interrelated constituents that include confidence among the working staff, 
understanding of the concept, and the ability of the administration to perform the required work that allows change and close examination. It is clear that the constituents concerning the professional learning communities avail confidence among the staff at all levels (teachers \& leaders). They also work to raise awareness for the improvement and development of the schools. The professional learning communities are different as compared to other learning communities as it can predict the future problems, care about the outside environment, and performs continuous research on improvement and development. It also plays a significant role in rewarding and enhancing growth, initiative, and innovation. Moreover, the exploration and participation in information exchange are encouraged through identification of the posts.

Pedagogic leadership has also got some interesting applaud in developing new roles and relationships within the school and PLCs, as it works parallel with strategic leadership. But, the quality and nature of leadership is substantially affected by the school culture; therefore, it might be hypothesized to its engagement in a PLC. A predefined condition should be considered to improve learning in the school culture that balance interests of all stakeholders, emphasizes on people instead of systems, makes time for learning, links a holistic approach to issues, supports open communication, makes people believe they can change their environment, believe in teamwork, and has approachable leaders (Mahimuang, 2018).

\section{The Concept of Distributive Leadership}

The distributed leadership is the first and foremost in leadership practice, rather than leaders or their roles. It is about leadership practice and interaction, not simply roles, positions, or actions of heroes. Therefore, distributed leadership focuses on a different model within the school, where the distinctions between followers and leaders tend to blur (Gronn, 2000). It incorporates the activities and efforts of various groups in a school, who work as leading staff in the instructional change process (Spillane \& Camburn, 2006). The distributive leadership varies on the basis of the leadership pattern; such as the democratic leadership, participative leadership, and cooperative leadership. It also varies from the concept of 
devolving power, the hierarchal, and traditional power. The distributive leadership relies on the distributing duties, roles, and activities of the staff according to their abilities and interaction with individuals.

The concept of distributive leadership has achieved much credibility, in particular, within the educational discourse. The increase of distributive leadership to prominence can be categorized in contemporary transformation of the public service that requires greater alignment, weakened classifications, and a societal culture. It also focuses on the new work order pertaining to the knowledge economy, where people work and learn using spatial and temporal codes beyond bureaucratic enclosures. Particularly, distributive leadership attracts in education and its potential lies in bringing school enhancement (Hairon, Goh \& Lin, 2014).

Arguments have also been made on the possibility of distributive leadership influence on instructional attributes of leadership, and leveraging to enhance instructions. Along with transformational leadership, distributive leadership is assumed to be more influential as compared to transactional leadership to affect school environment and climate, and improve the instructional capacities of teachers. Due to its inadequate empirical consensus, its potential remains intuitively attractive and quite compelling even though the literature remains agnostic on student achievement (Peters, Carr \& Doldan, 2018).

\section{The Concept of Participative/Shared leadership}

Participative leadership has been defined as a type of leadership, which is highly based on the individuals' confidence and capability to be responsible. They are the leaders, who have self-security, a positive understanding of themselves, and are confident about the others. It could be understood that the pattern of shared leadership depends on making shared decisions between the leaders and the staff. They are allowed to practice their leadership roles apart from getting benefit from the views and experiences of their colleagues at school. This is carried on through an atmosphere filled with confidence and mutual respect. 
Shared values portrayed empirical attributes of PLCs that vary significantly from the theoretical classification of previous results and evidences. A possible justification for this discrepancy is that common ideology is perceived by teachers belonging to the local society and assumptions. Belief and perception are an important value for teachers' profession as it has a direct influence on student's learning. Therefore, teachers must attend and play a major role in student's learning and contribute their instructional initiatives and techniques constantly using any method in any conditions with their colleagues (Ahn, 2017).

\section{Principles of the Shared Leadership}

Huffman \& Hipp (2001) identified a set of principles that are concerned with the effective shared leadership and confirm the commitment of teachers to the principles includes identifying of a shared set of values and fundamentals that support all the aspects of school life and direct engagement of the staff with the basic value. The principle of shared leadership also contributes towards dissemination of the school shared objectives along with cooperative work for their accomplishment. Performance sets the base for learning to appreciate the value of the individuals' views, experiences and knowledge serves as a stimulant for preparing potential leaders. Not only this, but it also stresses towards being accountable for the shared responsibility to improve the opportunities for the students.

The leadership principles confirm that the individuals' participation in their views, experiences, and knowledge represent a central element for the identification of the school's vision and objectives. They also indicate the commitment of employees in realizing the vision and the shared objectives. Moreover, it accounted for the results through the cooperative work. The shared leadership refuses the supremacy of the leaders over his followers. Therefore, shared leadership is much concerned with the construction of a professional learning community inside the school. This type of system needs all the necessary constituents that ensure effective learning and teaching process, providing an environment that assists in building a positive 
conjoint relation, keenness to the participation of the members of local and school society, and providing them with innovation and invention opportunities.

\section{Methods}

\section{Study Design}

The study has adopted a descriptive approach to describe the primary variables. It is worth mentioning that there are several attempts that have delivered the concept of scenario, its purpose, and the way of utilizing it. Qualitative research approach has been applied to assess the subject matter of the study.

\section{Study Procedure}

The current study is significant as it has adopted one of the developmental approaches, which simultaneously represents one of the contemporary trends in school improvement. The study has provided the necessary knowledge and explained the concept and ontology of professional learning communities, and its major principles through in-depth literature searches. It has incorporated the characteristics, patterns, and the leadership skills associated with the development of the professional learning community for developing comprehensive understanding essential for transformation of the conventional schools. Moreover, it has increased the concern of school leaders and staff about the fruitful cooperative work for the improvement and development projects in terms of their planning, organizing, implementation, and evaluation. It has also suggested the perspective for shifting the traditional paradigm of schools into professional learning communities based on the adoption of modern leadership patterns. 


\section{Results and Discussion}

Based on the literature search, the study has found that professional learning communities are characterized by their ability to predict the potential problems that school might encounter in the future (Huffman \& Hipp, 2001). It also observed that professional learning communities care for schools by emphasizing on the three major elements including; the cooperative work, the interaction among the professional staff, and harmonious care for learning in a cooperative environment.

\section{Reforming and developing schools}

The study found that one of the main objectives of professional learning communities is raising the academic performance of the school. The schools that adopt the professional learning community's system gain a high rate of achievement. Therefore, the school leaders, who have been shifted to professional learning communities, mainly focus on conducting standard tests to get information that assists them in following the learner's progress. This is evident from the findings of Louis (2008), who discovered that the students achieve a high rate of performance at schools under the professional learning communities. Similarly, Wong (2010) ascertained that the students' individual achievement in mathematics is positively correspondent with the increase in school learning level, which ultimately indicates that the school is part of a professional learning community. The professional learning community needs to create an environment that assists in the learning process, in case school wants to change and reform (Bryk, Camburn, \& Louis, 1999).

According to Constructive Social Theory, the focus has been shifted from individual learner to learners in a zone of a social group. In the same context, the present study illuminates that the new learning models are based on the progress that has been achieved in theories and research during the last 40 years, indicating that the students are responsible for building, discovering, expanding, and converting knowledge; while, the teachers are responsible for the facilitation of the learning process. In it, the students synthesize their 


\section{Alkrdem - Contemporary Educational Leadership}

own knowledge effectively because education is initiated by learners themselves and not by teachers; whereas, the teachers strive to develop students' skills and competencies. Learning is a personal process among students and teachers but it is also a social one when students and teachers work together. In order to effectively contribute to the process of continuous improvement, teachers are required to undergo a continuous professional development plan throughout their professional life.

The study also highlighted that the transformation of the conventional school can occur on the basis of the five principles, which are required for building a professional learning community. These principles have been defined by Hord (1997), which include participation, supportive leadership, shared vision and values, collective innovation, and supportive conditions. In the professional learning community, the principal of school exchange leadership traits and skills with the staff while he also participates in the group work in a collective and democratic manner. It makes the learning community distinct by having a shared vision and mission, and all the staff perceives their shared responsibilities towards the realization of goals. When the employees work together, they collaboratively look for new exchangeable knowledge that positively influences their practices inside the school. The supportive situations to shift schools to professional learning communities require the active participation of individuals in natural and structural situations, representing the organizational aspect of the school.

The present study realizes that the conversion of school into a professional learning community grounds on building and developing the capacities of the working staff to practice various leadership activities and roles. There are multiple practices that assist in building the school capacities as professional learning communities, where leadership plays an instrumental role. In reflective practice, the teachers reflect their practices and test their learning alternatives at school. Their reflections and research efforts could be known from their orientation towards collecting a large package of information regarding the school or the class. Organizational resources at schools provide suitable office resources for professional development. Employees in such schools are keen to continuously study the 
most recent research conducted in the field of teaching and learning. The interactive teaching methods enhance the process of teaching and learning in a cooperative fashion. Whereas, the schools avail several learning opportunities for parents, students, and employees.

\section{Requirements for Building Learning Communities}

The present study states that there exists a need for requirement which can assist in the transformation of the conventional schools into professional learning communities. In this regard, Cormier et al. (2009) identified a set of the necessary requirements highlighting that the adoption of a contemporary leadership pattern is identified as a foremost aspect that supports the engagement of employees. The professional learning communities require a leadership pattern, where the employees have the share in the process of decision-making and the exchange of power. The leaders also work to build the leadership capacity among their colleagues and are also concerned with the improvement of student's achievement (Bartlett, 2006). Providing a healthy relational atmosphere to the school leader will be also significant; so that, the school's staffs are able to score high in learning. The present study identifies that the distribution of the leadership tasks and responsibilities among the school staff as per their abilities would be also beneficial. Building up a professional learning community requires the leaders to focus on learning and researching the new strategies (Kilpatrick, Jones \& Barrett, 2003). The other factors recognized for forming a building learning community includes constructing organizational structures that support the cooperation culture among the employees. In it, the educationalists are aware of the value which the group work brings towards the achievement of the learning objectives. Another factor is the building of the confidence among the members of the school community which is considered as a fundamental concern for the success of the cooperative work in professional learning communities. The development of the professional development culture is inclusive of the support, especially from the staff. It depends on a mutual vision and collective work, where the leader is considered as a lead learner. The leaders of professional learning communities give much attention to the development of leadership abilities at their schools. Similar is the role played by the work teams. The importance of work teams is associated with 
technical or modern style, which helps to understand and accept the persons at work. It also helps in determining the dimensions of their behaviors such as motivations, readiness, and abilities to think and innovate. It also enhances support, confidence, mastery, and realization of goals.

\section{Leadership Patterns to Convert Schools into Professional Learning communities}

The current study observes that the adopted pattern of leadership at schools possess an impact on the way its goals are achieved and enhancing employees' standards. The leadership mode has a great impact on the performance of the staff, in the form of hindrance, motivation, restriction, liberty, and encouragement to their talents and capacities (Carrol, 2009). There is not a single mode of leadership, but there are multiple divisions that appear and vary according to the way they are visualized. There is a central leadership that allows a mild proportion of empowering in terms of decisionmaking. The decisions are made by senior administrative leaders. The minor administrators are empowered and the decision-making is not restricted to the senior leadership in decentralized leadership. The classic division of leadership divides it into dictator authoritative leadership, chaotic leadership, and democratic leadership. Therefore, the present study believes that the contemporary school leadership perspective ascertains the importance of education and the need to engage the staff and the concerned parties in leadership activities. It also affirms the importance of distributing power and exchanging the leadership roles among them. It is highly consistent with the necessary requirements to convert schools into professional learning communities.

\section{Distributive Leadership and the Professional Learning Communities}

The distributive leadership is considered as one of the contemporary leadership patterns that have emerged recently in the learning communities. There is a substantial impact of the distributive leadership in building professional learning communities. The distributive leadership at the school is based on several important principles, which are represented by Woods et 
al. (2004). On basis of the dominated values, objectives, and practices, the school culture needs to be characterized by a sort of cooperation to support teamwork. The staff needs to consider themselves as learners that provide them with a higher rate of confidence. The members of staff need to feel that they are valued, have confidence, and are supported by the leader. The staff needs to take part in building a conjoint vision for school apart from improving and casting the vision. Staff should feel comfortable towards their responsibilities and they need to feel supported and empowered when taking a risk. Therefore, the distributive leadership mode cares basically for spreading the cooperation culture among the staff and their engagement in building a conjoint vision at school. It also adopts structures based on work team and allows the empowerment of staff and supports their autonomy. It also provides the staff with chances; so that, they acquire the abilities and skills to bear the leadership responsibilities. As a result, they become a team of learners under the framework of a professional learning community. Carole and Michele (2008) indicated multiple principles of distributive leadership, which are represented in adopting systems that get benefit from the experience of all members of the organization. It has also been represented in doping the organizational structures that support policy distribution arrangements and dissemination of cooperation culture among the individuals accounting for views multiplicity and diversity.

The distributive leadership depends on teamwork and enhancement of the networking skills within the school premises. It also relies on a magnitude of professional respect among the organization members and close relations (Kimber, 2003). It indicates that the distributive leadership depends on a group of persons representing the whole organization in the school premises. They formulate teamwork as the members communicate with each other easily by building cooperative relations characterized with confidence and respect.

\section{Value of Distributive Leadership to the Professional Learning Communities}

The value of the distributive leadership to the professional learning communities has become distinct in several indicators, which are coined by 
Mujis and Harris (2003). The indicators include providing support to school leaders in their learning and development endeavors. It involves motivating all the staff and the concerned people to work together as a cooperative team to connect with the development of school mission for bringing in significant improvements. Another indicator address devolution of the concerned parties and allowing them to participate in a collaborative manner to make decisions and distribute responsibility for infusing the feeling of maximal accountability. Following it is the factor of staff cooperation that identifies and realizes the learning objectives at school. The indication also includes identifying the teams that work to take power, responsibility, and training to improve the activities which occur within the school. The teams are encouraged to join the conjoint decision making and look for effective solutions. Therefore, it is clear that the distributive leadership mode is much concerned with converting schools into professional learning communities via support of the leaders for learning and realizing its objectives.

The distributive leadership pattern is associated with the transformation of schools into professional learning communities, where the staff is able to participate, innovate, and experience new practices (Wilson, 2005). It shows the importance of distributive leadership in converting schools into professional learning communities, where the team members learn communication and leadership skills. Practicing of this leadership makes the staff and laborers feel confident and respected, which eventually leads to support in decisions pertaining to risk. It facilitates the adaptation of the cooperative culture structures where the staff realizes and supports the school vision. It further expands to rewarding and challenging the staff where they are continuously considered as learners. Cole (2009) indicated the range of school's engagement in converting schools into professional learning communities. The assistant factors contribute to meet the requirements of the professional learning communities 


\section{Participative/Shared leadership}

Participative/Shared leadership is considered as a type of leadership patterns that have emerged in the literature of the temporary organizational ideology. It is practiced by several leaders at schools and its efficacy has been shown in shifting schools into professional learning communities.

\section{Importance of Shared Leadership in the Professional Learning Communities}

Slater (2008) identified the importance of shared leadership. The structures operate to support the participation in developing the school as a learning community. The shared leadership vividly appears in the daily flow of school activities, and all the staff members are encouraged to become a leader by providing them suitable tasks to carry out. The experiences of the students, staff, and parents are taken into account because they are considered as resources. The leadership patterns for work and activity are encouraged and enhanced by disregarding the module that is being studied. Therefore, it is believed that the shared leadership depends on several elements involved in the conversion of school into a professional learning community. These elements are represented in the suitable structure that supports the staff's participation and urges them to bear leadership responsibility, which is congruent with the school context and the tasks performed by them. The shared leader seeks to develop the staff's performance via two stimulation strategies, which are identified by Joanne and Jorunn (2009). As per the study, the first stimulation strategy integrates the organizational commitment which advocates that motivation theories support the self-representation and self-control as central stimulating factors. The shared leader provides opportunities for the staff to participate and exert more efforts in the process of decision-making. This participation increases their confidence in the information they have discovered. The other strategy infuses in the concept of empowerment where an initiative is taken by the leaders for some improvements and for bearing a conjoint responsibility related to the various activities concerned with planning and control. They have a feeling of autonomy, which helps in formulating the basic empowerment constituent that supports their self-representation and self- 


\section{Alkrdem - Contemporary Educational Leadership}

control. It also increases their motivation for accomplishing the school improvement. The school leaders need to practice the shared leadership via several behaviors including; respect of time, attending training workshops, presenting beneficial workshops, developing confidence via spreading the culture of equality and adopting non-hierarchal or informal structures.

\section{Characteristics of the Leadership Pattern}

The set of characteristics is necessary for converting schools into professional learning communities have been provided by Slater (2008). According to him, leadership practices are separated from position capacities and linked with experience. The leadership is an attribute that is not associated with a certain person or position, rather extends to include every member of the school team. It relies on experience rather than functional authority in practicing the leadership work at schools. The leadership responsibilities and tasks need to be distributed to formal and informal leaders. This encourages the members of school society to practice leadership roles and activities. Another characteristic of the leadership pattern involved the formation of the participative culture that has been supported by all the concerned parties. The leaders, staff, and the concerned persons are engaged in the process of decision-making. The members of the school and local society participate in leading a school; whereas, the members of the school society participate in the identification and spread of school vision and objectives. Additionally, the development of organizational structure includes the adoption of structures depending on the teamwork and empowerment of the staff crucial for their independence and participation in leadership. It also adopts the flexible and non-hierarchal structures that allow individual learning and initiate change. They also seek to be capable of quickly adapting to the inconstant environmental situations.

Adoption of an organizational culture supports the preparation of an environment that assists in setting up positive cooperative relations among the members of the school society. It also creates a cooperative culture among the school society members and enhances the cooperative modes while simultaneously performing various activities. It is also necessary to 
enhance the mutual respect and confidence between leaders and members of the school team. Moreover, the support of sustainable development provides continuous professional development opportunities to the members of the school team and care for building the leadership capacities to members of the school society. Supporting the learning culture has been considered as a team of learners, who care for cooperative learning among the members of the school team. It also urges the members of the school team to discover new challenges for learning through acquiring knowledge. Supporting innovation and renovation is facilitated by the promotion of the strategies that empower the staff and members of the team. It is necessary to develop the capacity of the team to convert new ideas and individual knowledge to procedures, practices, and innovative services. The opportunities need to be availed by the members of the school team for trying out new ideas and practices.

The study has inferred a set of the points of weaknesses and strengths by reviewing some literature and studies. The points of strength include a change of traditional image towards school, caring for expanding the participation scope concerning school leadership and decision-making, provide an appropriate learning environment where positive values dominate, and urging the school society to change and renovate. Whereas, the point of weakness includes; absence of school conjoint mission and vision, domination of centralized culture across the school, refrainment from the newly introduced approaches in leadership, and weak contribution of the concerned parties to decision-making.

On the basis of adapting some modern leadership roles, some perspectives have been formulated to convert the schools from the traditional image into professional learning communities. The steps involved in describing the current situation of school through the identification of weaknesses and strengths are related to converting schools into professional learning communities in the light of the dominant leadership mode are as follows;

- It is necessary to identify general trends regarding the conversion of schools into professional learning communities. The school needs to 


\section{Alkrdem - Contemporary Educational Leadership}

adopt non-centralization in learning administration and school leadership. The conversion of school into an isolated culture provides an open learning environment where all the concerned parties participate. This empowers the staff and supports their autonomy. The consolidation of participation of staff, parents, and relevant persons expand the scope of societal participation in the learning process to create a future vision of the school. The adoption of flexible organizational structures and teamwork at school aims to develop cooperation among the member of school society and facilitates the exchange of experiences, knowledge, and information. It is necessary to ascertain transparency and provide information to the concerned person for the learning process. This greatly depends on the knowledge and experience of staff, rather than their position in school leadership. The investment of information and communication technology provides a healthy atmosphere to create positive relations among the staff. Moreover, the adoption of innovation and renovation culture spreads the culture of reflection and thinking among the members of school society. However, the adoption of accountability for parents, local society, and the supreme authority holds significant importance.

- It is significant to understand the symmetrical dynamic concerning the conversion of schools into professional learning communities. The variables and forces impacting the conversion of schools into professional learning communities have been divided into forces and internal factors, and forces and external factors. The most important forces and internal factors include; school leadership type, organizational structure, school staff participation, quality training, and internal school learning environment, and availability of effective school information and networking systems. The forces and external factors are related to the external environment, in which the school operates that significantly affects the conversion of school into a professional learning community. These variables are represented as; changing the school's traditional image, get adapted to technological changes, caring for the teachers' professionalism, constructing a national board to ensure learning quality, and activating the role of civil community organizations. 
- The suggested scenarios are constructed for the conversion of schools into professional learning communities based on the adoption of temporary leadership types. After evaluating and exploring the current situation and the related aspects of weakness and strength, three scenarios have been suggested for the conversion of schools into professional learning communities on basis of the construction of temporary types of leadership. These include; the authoritative or current situation scenario, a reformative scenario where partial improvement takes place, and the creative scenario that depends on making a qualitative transition to the current situation (Al'isawy, 1998; Alice, 2008). In the following account, each scenario has been described through the identification of main assumptions.

The schools can be converted into a professional learning community by sticking to the school traditional image without developing it to a broad view. It is necessary to maintain the schools' isolated culture in the school premises and prevent it from spreading. All of the staff tends to participate in the conjoint vision, mission, and development planning. The continuation of following the bureaucratic approach in school leadership consists of leadercentered power. However, sticking to the organizational hierarchal structure eliminates the staff and the concerned parties from being involved in decision-making. The continuation of traditional work styles results in refrainment from adopting teamwork style with the absence of collective work. At the school level, there is a continuous refrainment of the members of the Trustee Council and parents from getting involved in decisionmaking. The societal participation from the concerned persons lacks due to the continuity of the limited relations between school and the outside society. Nominal advances of information and communication technology need to be used to support learning, which can be achieved by preserving the current situations through resisting change, being innovative, and avoiding experimenting ideas.

There are several consequences that are expected to take place if the reference scenario is adapted to change schools into professional learning communities. The attempt to change the traditional image of school into a professional learning community provides a place where every individual 


\section{Alkrdem - Contemporary Educational Leadership}

can learn effectively. It is necessary to acknowledge the necessity of documentation involved in the mission of the school as it has become one of the basic criteria imposed by the National Board to ensure learning quality. The adoption of decentralization approach ensures the involvement of staff and the concerned persons in decision-making, which virtually eliminates the leader's domination over the administrative issues. Reviewing the hierarchal organizational structure does not encourage the staff to make decisions. The school members fail to achieve their objectives as they refuse to adopt the work team and collective work styles to address problems faced by them. The implementation of the reference scenario for converting schools into professional learning communities is based on several justifications. It is difficult to change the current situation in a short time because the staff is accustomed to the current situation and the resistance to change has also increased.

The Reformative Scenario is based on making partial modern improvements and developments in the current situations without changing them fundamentally by enhancing the aspects of strength and address some of the weaknesses. A document consisting of vision and mission of school needs to be specified by the school leader without actual participation of the staff and other concerned persons in its formulation and implementation. The gradual elimination of traditional images at work attempt to build the work teams. The members of the Trustee Councils and parents are urged to provide their suggestions and views in the process of decision-making at school. Some attempts have been initiated by leaders and staff to invest in information and communication technology. The continuous development and updating for training activities and programs and the professional development has been delivered by school training departments. The school leaders need to be aware of the necessity of preparing a healthy atmosphere, in which the values of mutual respect, confidence, cooperation, and transparency spread. New practices and ideas are tried by the members of the school team to avail opportunity, which develops creative abilities and contributes towards renovation. 
It is necessary to acknowledge school as a professional learning community and disregard its traditional image. The staff and the concerned persons are involved in identifying, formulating, and implementing the vision and mission of a school. The gradual reform of school organizational hierarchy might be done in a way that allows the staff involved in the process of decision-making. The school staff, leaders, and members of school society need to be aware of the importance of spreading the culture of collective and cooperative work. The school staff may be allowed to engage in leadership by addressing their perspectives and suggestions. Moreover, they also need to be aware of the importance of adopting conjoint models in leading school. It is important to prepare a healthy atmosphere in which the values of mutual respect, confidence, cooperation, and transparency spread.

School leaders who are interested to promote PLCs for school-based curriculum innovation and development; shared values, distributive leadership, and leadership patterns can be practically implemented considering different school contexts. Developing the skills, attitudes, and knowledge towards a shared goal have to take into emphasis both pragmatic and Confucian work ethics. Impact must take into consideration balancing between task efficiency and effectiveness, and the cultural values of respect for hierarchy and elders. For instance, principals initiating to promote distributive leadership need to develop knowledge in the subject area through informal leaders.

\section{Conclusion}

The implementation of reformative perspective increases the desire towards the implementation of decentralization. It is important to assure that the work teams are successful in fulfilling all tasks and solving the problems that are encountered by the leaders and members of the team. The concern towards investment in the information and communication technology has been growing to build the leadership capacities of the members of teamwork. Therefore, the reformative perspective attempts to make some partial amendments on the current situations to deepen some positive aspects and address some negative aspects. The innovative scenario relies on the 
fundamental change that delivers a qualitative transition on the current situations. It supports the aspects of strength, addresses the aspects of weakness, and relies on innovative and creative thinking. The development of innovative and creative skills is necessary to convert schools into a professional learning community. The adoption of an organizational culture supports innovation and renovation as it urges the members of the school team for experimentation. The increase in the empowerment of school team members provides them with a certain degree of autonomy to formulate and execute decisions. Diverse programs and activities need to be invented to train the leaders and staff. Apart from inventing new practices and knowledge contributing to the development of creative capacities, it is necessary to believe in the need to change and renovate. All the decisions at school levels are taken by confirming the societal effective participation and the joining of the civil community. There are many concerns with the development of administrative and organizational staff that assists in building positive and cooperative relations. Therefore, the application of the innovative scenario contributes towards attainment of the desired change in future in terms of the professional learning communities' requirement.

\section{Funding}

This research received no external funding

\section{Acknowlegments}

The author is very thankful to all the associated personnel in any reference that contributed in/for the purpose of this research.

\section{Conflicts of Interest}

The author declare no conflict of interest. 


\section{References}

Al'isawy, I. (1998). The Scenarios: A study on the concept of scenarios and ways of building them in Wgypt Awrag Project 2020. National Centre for Educational Research \& Development, 1, 7.

Al-Husaini, A., \& Zaghlool, E. (2005). The Organizational Confidence and the Effectiveness of School Performance in Egypt Education. The Egyptian Association for Comparative Education \& Instructional Administration, 17, 21-95.

Ahn, J. (2017). Taking a Step to Identify How to Create Professional Learning Communities--Report of a Case Study of a Korean Public High School on How to Create and Sustain a School-Based Teacher Professional Learning Community. International Education Studies, 10(1), 82-92. Doi: doi.org/10.5539/ies.v10n1p82

Alice, G. (2008). Successful Scenario Planning.

Bartlett, K.M. (2006). Professional Learning Community Within a State Education Organization: An Action Research Study. ProQuest.

Bennett, C. S. (2017). Professional Learning Community Impact on Student Achievement. Unpublished Ph. D. Dissertation. Canada: The Education Department, Carson-Newman University.

Bryk, A, Camburn, E, \& Louis KS. (1999). Professional community in Chicago elementary schools: Facilitating factors and organizational consequences. Educational administration quarterly. 35(5):751-81. doi:10.1177/0013161x99355004

Carole, K., \& Michele, F. (2008). Distributed Leadership: Leadership in Context. UNESCO- APEID International Conferee: Quality Innovations for Teaching and Learning. Bangkok, Thailand.

Carrol, S. (2009). Relational Leadership. A Key in The Framework of School Leadership for the Children's Sake by Nicolle Hutchinson. Available at: http://childlightusa.word press.co.

Cole, R. (2009). The distributed leadership experiment: First year impacts on school culture, teacher networks, and student achievement (Doctoral dissertation, University of Pennsylvania).

Cormier, R, Olivier, DF, \& Lafayette L. (2009). Professional learning committees: Characteristics, principals, and teachers. In Annual Meeting of the Louisiana Education Research Association, Lafayette, Louisiana. 
Dettinger, K. \& Brower, A. (2003). What is a learning community? About campus EBSCO.

Gronn, P. (2000). Distributed properties: A new architecture for leadership. Educational management \& administration. 28(3):31738.doi:10.1177/0263211x000283006

Gwin, T.E. (2008). A study of the implementation of schedule embedded faculty professional learning communities in a suburban Massachusetts high school. Boston College.

Hairon, S., Goh, J. W. P., \& Lin, T. B. (2014). Distributed leadership to support PLCs in Asian pragmatic Singapore schools. International Journal of Leadership in Education, 17(3), 370-386. Doi: doi.org/10.1080/13603124.2013.829586

Hord, S.M. (1997). Professional learning communities: Communities of continuous inquiry and improvement.

Huffman, J.B, \& Hipp, K.A. (2001). Creating communities of learners: The interaction of shared leadership, shared vision, and supportive conditions. International Journal of Educational Reform. 10(3):27281.

Joanne, W., \& Jorunn, M. (2009). Shared Leadership Principle in John Mac Beath and Daniel Dempster. Connecting Leadership and Learning. (London: Routledge).

Kilpatrick, S, Jones, T, \& Barrett M. (2003). Defining learning communities. Centre for Research and Learning in Regional Australia.

Kimber, M. (2003). Does size matter? Distributed leadership in small secondary schools.

Louis, KS. (2008). Creating and sustaining professional communities. Sustaining professional learning communities. 1, 41-57.

Mahimuang, S. (2018). Professional Learning Community of Teachers: A Hypothesis Model Development. In The 2018 International Academic Multidisciplinary Research Conference, ICBTS.(July 20-22, 2018): 229 (Vol. 23).

Melton, C. (2007). An introduction to learning communities under the framework of staff.

Moilanen, R. (2001). Diagnostic tools for learning organizations. The learning organization. 8(1):6-20. doi:10.1108/09696470110366507 
Muhammad, G. (2009). The organizational support to teachers and creative environment at general secondary schools in Egypt.

Muijs. D, \& Harris, A. (2003). Teacher leadership-Improvement through empowerment? An overview of the literature. Educational Management \& Administration. 31(4):437-48. doi:10.1177/0263211x030314007

Peters, T., Carr, R., \& Doldan, J. (2018). Strength found through distributed leadership. Educational Viewpoints, 32-34.

Slater, L. (2008). Pathways to building leadership capacity. Educational Management Administration \& Leadership. 36(1):55-69. doi:10.1177/1741143207084060

Spillane, JP, \& Camburn, E. (2006). The practice of leading and managing: The distribution of responsibility for leadership and management in the schoolhouse. American Educational Research Association.

Sulaiman, E. (2009). The Organizational Struggle and Leadership Styles to Leaders of General Education Schools in Egypt.

Watson, C. (2014). Effective professional learning communities? The possibilities for teachers as agents of change in schools. British Educational Research Journal, 40(1), 18-29. Doi: doi.org/10.1002/berj.3025

Wilson, C.L (2005). Principal leadership school climate and the distribution of leadership within the school community.

Wong, J.L. (2010). What makes a professional learning community possible? A case study of a mathematics department in a junior secondary school of China. Asia Pacific Education Review. 11(2):131-9. doi:10.1007/s12564-010-9080-6

Woods, PA, Bennett N, Harvey JA, \& Wise C. (2004). Variabilities and dualities in distributed leadership: Findings from a systematic literature review. Educational Management Administration \& Leadership. 32(4):439-57. doi:10.1177/1741143204046497 
Mofareh Alkrdem Associated Professor of Educational Leadership in the Departent of Educational Administration and Supervision of King Khalid University. Teaching/Lecturing Contributions: Lectured, directed, and taught advanced lessons, provided presentation support, trained apprentices and developed courses' material and tools. Advised and supervised students in their research work and complex assignments. Prepared new study materials and development programs for graduate and undergraduate students. Research Interests: Educational Leadership, Educational Administration, Educational Supervision, Educational Planning, and Educational Economics. Contact Address: College of Education. King Khalid University. P.O.BOX: 157. Abha, 16411, Saudi Arabia. Phone: 00966500408221

E-mail: msalkerdem@kku.edu.sa 